\title{
perifèria
}

Número 20 (1), junio 2015

http://revistes.uab.cat/periferia

\section{(Re) conocer, diagnosticar y cuidar dolores que "no se ven": narrativas encontradas sobre la migraña en Buenos Aires, Argentina}

Romina Del Monaco

Instituto de Investigaciones Gino Germani-Universidad de Buenos Aires-

CONICET ${ }^{1}$

DOI: http://dx.doi.org/10.5565/rev/periferia.454

\section{Resumen}

En este artículo se investiga la forma en que se construye el diagnóstico biomédico de la migraña, los relatos de aquellos que padecen estos dolores de cabeza y de sus vínculos cercanos. A diferencia de otros padecimientos crónicos, la migraña es un dolor con un doble estatus. A pesar de que los saberes expertos legitiman y dan forma al diagnóstico (aunque se carece de una etiología clara y precisa), se observan explicaciones múltiples y fragmentarias acerca de los motivos que producen el malestar combinando aspectos biológicos con dimensiones sociales tales como los modos de vida de quienes padecen. Asimismo, las formas de cuidar y convivir con la dolencia están atravesadas por una serie de sentidos atribuidos socialmente al dolor que se asocian con las excusas y exageraciones.

La perspectiva teórica-metodológica se inscribe en el dominio de la antropología de la salud, siguiendo los lineamientos de la investigación cualitativa y, específicamente, el análisis de las narrativas. El trabajo de campo consistió, en primer lugar, en la realización de entrevistas en profundidad y observación participante en un hospital público del Área Metropolitana de Buenos Aires, Argentina. En segundo lugar, a través de la técnica de bola de nieve, se realizaron entrevistas a otras personas que padecían migraña y vínculos próximos (parejas, familiares, conocidos) por fuera de la institución.

Palabras clave: Dolor crónico- Migraña- Biomedicina-Narrativas-Legitimidad

\section{Abstract}

This article investigates the diagnostics constructions of migraine and narratives of people with this kind of headache and their families. The conflicting characterization for migraines laid a double statute in these headaches. Even though the expert

1 Enviar correspondencia a: Romina Del Monaco, dirección electrónica: 


\section{perifèria}

Número 20 (1), junio 2015

http://revistes.uab.cat/periferia

knowledge legitimize the diagnosis -although there is no clear etiology-, multiple and fragmented explanations are promoted from the patients and their environment, that are expressed in the various social meanings attributed to the pain. In some cases, these explanations are traversed by social constructions and the common meaning linking this pain with excuses and exaggeration.

The methodological perspective is inscribed in the domains of health anthropology, following the alignments of qualitative investigation and, specifically, the analysis of the narrative. The field work consisted, in the first place, in interviews in depth and participant observation in a public hospital of the metropolitan area of Buenos Aires, Argentina. In second place, through the snowball technique, interviews were made to other people with migraines and close ties outside the institution.

Keywords: Chronic pain-Migraine-Biomedicine-Narratives-Legitimacy

\section{Introducción}

Existe un tipo de dolores de cabeza crónicos que la biomedicina categoriza como "migraña" cuyas apariciones pueden ser frecuentes (aunque se desconocen los motivos). Estos dolores suelen estar acompañados de nauseas, vómitos, molestias e intolerancia a la luz, al ruido, a los olores y, generalmente, afectan a la mitad de la cabeza. A partir de distintos estudios epidemiológicos, se trata de un problema mundial, con variaciones regionales, que afecta a personas de todas las edades, niveles de ingresos y zonas geográficas. De hecho, la OMS señala que la prevalencia de la migraña es alta calificándola como una de las 20 enfermedades más discapacitantes con amplias consecuencias en distintos ámbitos de la vida y con incidencias tanto a nivel físico como emocional que interviene en el desempeño laboral y dificulta el normal desarrollo social ${ }^{2}$.

Más aún, el análisis de estos dolores de cabeza cobra particular relevancia debido a las transformaciones socioeconómicas relacionadas con el despliegue del capitalismo contemporáneo y la implementación del neoliberalismo (Harvey 2005). Es decir, ante el lugar protagónico que adquiere el trabajo en las sociedades capitalistas, las enfermedades, en especial aquellas que se prolongan indefinidamente en el tiempo, amenazan entre otras cosas, la continuidad laboral. Si bien son escasos los estudios epidemiológicos con cifras tanto a nivel mundial como local, profesionales especialistas en la migraña estiman que este dolor afecta

2 "La OMS reconoce a la migraña crónica como enfermedad incapacitante". Télam [Sociedad], 15 de agosto de 2012. Disponible en http://www.telam.com.ar/nota/34995/ [Consulta: enero 2013]. 


\section{perifèria}

Número 20 (1), junio 2015

http://revistes.uab.cat/periferia

al $14 \%$ de los individuos en países occidentales y, en promedio, al $16 \%$ de las mujeres y $7 \%$ de los varones a nivel mundial. En la Argentina, investigaciones efectuadas en el ámbito de la biomedicina sobre pequeños grupos y poblaciones acotadas a determinadas regiones permiten estimar mediante proyecciones que la migraña afecta en este país, aproximadamente, al $12 \%$ de la población general (Zavala y Sarabia 2006). A pesar de estas cifras que muestran la incidencia de la migraña a nivel mundial, estos dolores se han convertido en una forma rutinizada de sufrimiento que pierde importancia ante otros padecimientos asociados a "catástrofes de salud" y que tienen directas consecuencias en la supervivencia de determinados conjuntos y poblaciones (Kleinman 1994). No obstante, la investigación sobre estos dolores de cabeza ha posibilitado identificar una serie de aspectos y problemáticas que lo diferencian de otros malestares crónicos abordados por las ciencias sociales constituyendo su estudio un verdadero aporte a la temática sobre sufrimiento y cronicidad desde una perspectiva antropológica.

En primer lugar, teniendo en cuenta que la biomedicina tiene un modo de concebir a los sujetos (Dias Duarte 2003) y de realizar diagnósticos donde se privilegian aspectos biológicos fundamentados en evidencias empíricas (Camargo 1997; Lock 2010), estudios antropológicos plantean la falta de reconocimiento de los médicos a los relatos de los pacientes con dolencias crónicas (Good 1994a; Kleinman 1994; Jackson 2000). En cambio, en el caso de la migraña, la construcción diagnóstica se da a la inversa $y$, a partir de las palabras de quienes padecen, proceso que no se ha encontrado en otras enfermedades crónicas.

Más aún, lo paradigmático y particular de la migraña, a diferencia de otros dolores/enfermedades investigadas, es que en este caso si bien los profesionales "escuchan" los síntomas de los pacientes, socialmente y en los vínculos cercanos hay una serie de sentidos y connotaciones negativas vinculadas a estos dolores de cabeza que complejizan tanto la "creencia" como los modos de cuidar este padecimiento. 


\section{perifèria}

Número 20 (1), junio 2015

http://revistes.uab.cat/periferia

\section{El estudio}

La perspectiva teórico-metodológica se inscribe en el dominio de la antropología de la salud siguiendo los lineamientos de la investigación cualitativa. El trabajo de campo fue desarrollado durante los años 2010 y 2011 en el servicio de neurología de un hospital público del Área Metropolitana de Buenos Aires. Dentro de la institución médica se realizaron 40 entrevistas en profundidad a personas con migraña (28 mujeres y 12 varones), el rango etario iba desde los 21 hasta los 65 años. El ingreso de los pacientes a la institución se realizaba mediante turnos previamente acordados y, en general, luego de consultas con otros profesionales médicos clínicos y/o neurólogos- del hospital los derivaban al gabinete especializado en cefaleas. Las entrevistas en profundidad a pacientes se realizaban luego de la consulta con el profesional especialista en migraña y el criterio para la selección y realización de las mismas fue que hayan sido diagnosticados con este tipo de dolores de cabeza previamente por el médico.

En el mismo hospital se entrevistó a 18 médicos neurólogos. La decisión de incluir profesionales de la neurología reside en que desde la biomedicina es esta especialidad la encargada de realizar el diagnóstico y tratamiento de la migraña. Otra de las técnicas empleadas fue la observación participante en los siguientes espacios del hospital: en primer lugar, fue posible presenciar una serie de ateneos donde profesionales especialistas en migraña presentaban ante los residentes las particularidades de este tipo de dolores de cabeza (distintas teorías sobre su origen, etapas necesarias de las consultas, modos de prevención, etcétera). En segundo lugar, la sala de espera para las personas que se atendían por migraña era compartida con pacientes que concurrían al hospital por diferentes problemas neurológicos. La atención comenzaba alrededor de las 9 de la mañana; y entre esa hora y hasta las 10 , eran los momentos de mayor concurrencia en ese servicio dado que, si bien las personas tenían turnos tomados previamente, se las llamaba por orden de llegada. Estos diálogos permitieron conocer los cambios y las consecuencias durante los tratamientos, así como diversas cuestiones de la cotidianidad con los dolores de cabeza que no se habían mencionado en las entrevistas previas.

Luego, durante los años 2012 y 2013 se llevaron a cabo, a través de la técnica 


\section{perifèria}

Número 20 (1), junio 2015

http://revistes.uab.cat/periferia

bola de nieve, entrevistas por fuera de la institución a 22 personas (mujeres y varones adultos de 21 a 65 años) vinculadas, directa o indirectamente, con quienes tenían migraña. La selección de los informantes se llevó a cabo del siguiente modo: se consultó a los pacientes entrevistados si había personas vinculadas a ellos a quienes se pudiera entrevistar (es decir, vínculos próximos como familiares, amigos, parejas).

Tanto dentro como fuera del hospital se entrevistó personas de niveles socioeconómicos medios y medios-bajos, es decir, que están incluidos en el mundo del trabajo y/o el sistema de atención de salud -ya sea éste público o privado-, que viven en el Área Metropolitana de Buenos Aires. Este recorte del referente empírico permitió indagar y analizar los modos de padecer de manera crónica vinculados a las transformaciones que produce el capitalismo contemporáneo en quienes están "incluidos". La decisión de acotar la población de estudio al Área Metropolitana de Buenos Aires, se debe a que en dicha área geográfica se encuentra la mayor cantidad de instituciones y profesionales especializados en el tratamiento de estos dolores de cabeza. El examen de las entrevistas se realizó a través del análisis de narrativas, esta decisión se fundamenta y se ubica dentro de una trayectoria de estudios sobre sobre procesos de padecimiento, enfermedad y sufrimiento que recurren a esta metodología para acceder a las experiencias de las personas mediante el relato de situaciones y eventos vividos con el dolor (Good 1994a; Kleinman 1994; Grimberg 2000, 2003; Margulies 2010; Del Monaco 2012 2013). Esto no implica reducir la vida a la dimensión del discurso, ya que la experiencia excede siempre las posibilidades de su narrativización. No obstante, las narrativas permiten visualizar los modos en que los sujetos dan forma a distintas experiencias (Grimberg 2009) construyendo sentidos y significados a partir de los cuales, y en interacción con "otros", se organiza su propia biografía, la visión de sí mismos y de otros (Margulies et al 2006).

Resguardos éticos: esta investigación se adecuó a los criterios de consentimiento informado y confidencialidad que se aplican en los estudios sobre salud, con el fin de asegurar los derechos de los/as participantes, así como también de resguardar su identidad. Los sujetos entrevistados son mayores de 18 años. Para realizar el trabajo de campo en el servicio de salud se llevó a cabo el proceso de 


\section{perifèria}

Número 20 (1), junio 2015

http://revistes.uab.cat/periferia

evaluación requerido a través del comité de ética cumplimentando los requerimientos del hospital.

\section{Cronicidad y biomedicina: insuficiencias de los saberes expertos frente a dolores sin causa conocida}

A pesar de que en numerosas ocasiones las categorías de "dolor", "enfermedad" y "malestar" se utilizan como sinónimos, cada una de estas nociones involucra saberes, prácticas y experiencias particulares.

El caso de dolores categorizados como migraña es paradigmático porque, aunque es considerada una "enfermedad" por la mayoría de los profesionales entrevistados, no cumple con algunos de los requisitos básicos de saberes biomédicos tradicionales para ocupar dicho lugar. En primer lugar, carece de indicadores biológicos que den cuenta de su "existencia". En segundo lugar, y en directa relación con el primero, se desconoce su etiología. Por último, los tratamientos orientados al alivio de los síntomas y ya no a la curación- no garantizan que se modifique en el tiempo (intensidad, duración) la experiencia de estos dolores de cabeza.

Debido a estas características particulares, la migraña cuestiona parte de la legitimidad de los saberes biomédicos, permite distinguir entre dolores y enfermedades y marca límites dentro de la medicina basada en evidencia. Sin embargo, y a pesar de su particular construcción diagnóstica, los dolores crónicos categorizados bajo esa denominación son incluidos bajo la categoría de enfermedades dentro de los manuales internacionales de enfermedades (OMS 2012). A pesar de esta categorización, en los relatos de las personas con estos dolores de cabeza, las sensaciones y percepciones respecto de su legitimidad difieren de los criterios de los profesionales.

Y no, quién te va a creer que por un dolor de cabeza dejes cosas. No, decía que me descomponía del estómago, que me sentía mal... que me agarraba un cólico, cualquier cosa Yo por ahí para que no piensen que no esté inventando, les inventaba otra cosa (Hilda, 61 años). 


\section{perifèria}

Número 20 (1), junio 2015

http://revistes.uab.cat/periferia

Sí, porque el ser humano parece ser que uno... o es muy común el dolor de cabeza o mucha gente toma el dolor de cabeza como una excusa. No lo sé, no soy médico, y no le pregunto a la gente '¿Te duele en serio o me estás mintiendo?'. Entonces, uno siente que hay mucha gente que le duele la cabeza. Entonces, digo, o mucha gente tiene dolor de cabeza, o mucha gente usa el dolor de cabeza como una excusa. ¿Correcto? Entonces, cuando hay un migrañoso (risas) hay muchos que creen que está jodiendo (Hugo, 54 años).

En los relatos de Hilda y Hugo, como sucede con otros entrevistados, hay connotaciones que rodean a la migraña, y están dadas, entre otras cosas, por los diferentes usos y sentidos que se les otorgan socialmente a estos dolores de cabeza. Las enfermedades están rodeadas de significados y de luchas en torno a cómo vivirlas, entenderlas, asimilarlas en discusiones, formar estereotipos que influyen en las experiencias de sufrimiento (Sontag 2003).

Si bien no hay estudios que den cuenta de esta particularidad, el análisis de las narrativas tanto de pacientes como de sus vínculos cercanos, muestra una serie de sentidos en la vida cotidiana atribuidos a la migraña asociados con las excusas, mentiras y/o manipulaciones.

En un primer momento, cuando era chiquita y lloraba, mis papás se re preocupaban. Ahora, de grande, es un 'no exageres'. Pero yo digo que no estoy exagerando (risa), es el mismo dolor de siempre. $\mathrm{Y}$ a veces es más intenso y a veces no. A veces me la banco y ni digo cuando me duele la cabeza porque, si no, van a decir: 'Uh, a esta le duele la cabeza todos los días'. Pero a veces uno se tiene que callar por el qué dirán, aunque sea tu propia familia. Porque ya pasás a ser psicosomática que tiene todos los problemas. A vos siempre te duele algo... y no, es feo (Claudia, 29 años).

Los testimonios dan cuenta de la dificultad que tienen estos individuos frente a la frecuente desacreditación de su padecimiento. La migraña instala un tipo de legitimidad particular en la que la duda o creencia en la existencia de ese dolor descansa en la combinación de sentidos atribuidos socialmente (por parte de 


\section{perifèria}

Número 20 (1), junio 2015

http://revistes.uab.cat/periferia

profesionales médicos, pacientes y entorno) a la dolencia. En estos casos, la valoración y legitimidad social de determinados padecimientos crónicos disminuyen cuando entran en juego opiniones subjetivas y experiencias que no tienen fundamento en desórdenes físicos y, por lo tanto, en realidad objetivable (Good 1994b). Quienes tienen migraña dicen que las quejas de una persona por su dolencia son en gran parte significativas si -entre otras cosas- reflejan una condición física. Si no se puede encontrar un referente empírico al significado de esa queja, o si se padece de manera prolongada y por mucho tiempo, ésta se pone en duda.

Me ha pasado de salir con un poco de dolor de cabeza... y dije... se me va a pasar porque me voy a distraer, y apenas entré al bar, ni tomé un sorbo y ya me fui al baño a vomitar y tuve que volver con un dolor de cabeza terrible, sentía como que me explotaba la cabeza. Pero es un bajón, mis amigos a veces como que no entienden, los que ya están acostumbrados bueno, pero igual te dicen: '¿Otra vez?' (Mercedes, 25 años).

Mercedes contó que, cuando salía a bailar con sus amigos, no podía tomar alcohol porque "me explota la cabeza", y que ellos "a veces no entienden, y eso que están acostumbrados". La mayoría de los pacientes con migraña dijeron que los demás: "no lo pueden entender", "no pueden estar en el lugar del otro", "se ponen nerviosos".

Asimismo, a partir de dualismos como mente/cuerpo, razón/emoción, en disciplinas como la filosofía y la medicina, la cabeza ocupa un lugar protagónico en los mapas corporales, dado que se la asocia con el control y la regulación del resto del cuerpo. Por esto, la migraña permite analizar qué sucede cuando esta parte del cuerpo se convierte en un espacio de padecer. ¿Se transforma el dolor en una preocupación central de la vida de las personas? ¿O es algo más con lo que dicen convivir? Responder algunos de estos interrogantes implica examinar las articulaciones y tensiones entre saberes legos, expertos y los contextos en los que los malestares acontecen. Dichas relaciones dan cuenta de las características que socialmente se le otorgan a la migraña, que intervienen -como menciona Sabrina a 


\section{perifèria}

Número 20 (1), junio 2015

http://revistes.uab.cat/periferia

continuación- en las percepciones de los pacientes respecto de su dolor y de lo que piensan los otros sobre ellos y su malestar.

Ahora ya no me molesta pero, en un momento, como que me molestaba que la gente me mirara mal. Cuando era chica y me dolía la cabeza estaba eso de: 'iAy!, ¿tanto lío porque te duele la cabeza?'. Nadie me entendía. Ahora no me importa nada qué piensa el otro de mi dolor de cabeza. Creo que hay un prejuicio general que tenemos todos con respecto al otro cuando tiene un dolor y me parece que cuando no es un dolor justificable, fundamentado en una enfermedad grande, es una boludez. Se minimiza porque, aparte, el dolor de cabeza se cura con un Geniol, ya te lo dice la propaganda (Sabrina, 41 años).

Los prejuicios alrededor del dolor de cabeza se mantienen y reproducen desde hace tiempo y en eso las publicidades sobre fármacos para los dolores de cabeza tuvieron una importante función. "Cualquier dolor de cabeza se cura con un Geniol" decía un popular aviso publicitario décadas atrás. La mención de Sabrina a que "los dolores de cabeza se confunden con la migraña" es una afirmación recurrente en el conjunto de entrevistados. Los dolores de cabeza "los puede tener cualquiera, pero la migraña es otra cosa". Esa "otra cosa" la legitima la CIE-10, el manual internacional que, como fue señalado anteriormente, clasifica las enfermedades reconocidas por la biomedicina. En él, la migraña se encuentra tipificada como una enfermedad neurológica.

Dentro de la biomedicina se encuentran las enfermedades "tradicionales" en las que se identifican daños o lesiones visibles a partir de estudios y se procede a un tratamiento. En este caso se trata de un modelo curativo en el cual los profesionales indagan en los síntomas que consideran propios del malestar y se abstraen de los sujetos y de los elementos "periféricos" a la dolencia (Foucault 2008). Frente a estas enfermedades tradicionales se encuentran las enfermedades crónicas que se prolongan en el tiempo y modifican significativamente la cotidianidad de los pacientes. En ambos casos -enfermedades tradicionales y crónicas- se pueden rastrear evidencias biológicas como recursos de prueba de 


\section{perifèria}

Número 20 (1), junio 2015

http://revistes.uab.cat/periferia

su "existencia". Es decir, a través de estudios médicos se comprueba que algo se encuentra "fuera de los parámetros normales", lo cual otorga no sólo legitimidad al padecimiento sino también números, cifras y/o resultados -datos, en fin- que lo certifiquen.

Sin embargo, esos cuerpos propios de la biomedicina -estandarizados y biológicosno se corresponden con el paradigma de los dolores crónicos. La estandarización se modifica por la variabilidad de padeceres, de relatos y de vivencias con distintos malestares. En ese sentido, en los últimos años, desde las ciencias sociales se realizaron estudios que buscan discutir con la supuesta neutralidad epistemológica de la biomedicina. En especial, en torno a las diferencias entre lo "normal" y lo "patológico" ya que lo normal continúa vinculándose con lo "saludable" y "bueno", aspecto que padecimientos como la migraña contradicen desde el momento en que ni los motivos de su surgimiento ni las posibilidades de alivio están sistematizados.

En cambio al momento de definir biomédicamente los dolores crónicos, los profesionales entrevistados encontraban ciertas dificultades que no se habían presentado ante la definición de "enfermedad". Los profesionales describen los dolores crónicos como algo que "afecta la calidad de vida, es de larga duración, tiene una constelación que lo rodea, se prolonga más de 3 a 6 meses; tiene un componente emocional que limita, a diferencia del agudo, no está bien localizado y es difícil de tratar". En la mayoría de los casos se apelaba a la variable temporal, en algunos se incorporaban las modificaciones en la vida cotidiana. A diferencia de los dolores agudos, que desaparecen o empeoran al ritmo de la enfermedad de base, los dolores crónicos no necesariamente producen un deterioro corporal ni la muerte del paciente (Jackson 2000 2005).

Frente a la interrogación sobre las características de estos dolores crónicos, los profesionales hablaban con dudas, titubeos, ambigüedades $y$, en algunos casos, sonrisas. Al igual que en otras preguntas sobre la migraña, las respuestas estaban repletas de expresiones como: "se cree", "qué se yo", "depende", "no hay respuestas lineales en este caso"; "¿Te tengo que dar una definición?"; "sensación de dolor", "definición exacta no tengo", "es lo que yo entiendo", "¿querés la definición?" fueron algunas de las frases repetidas durante las entrevistas. En numerosas oportunidades los médicos encontraban dificultades tanto para dar 


\section{perifèria}

Número 20 (1), junio 2015

http://revistes.uab.cat/periferia

la definición de dolor crónico como de la migraña. Incluso, en una oportunidad una profesional señaló: "la verdad no sé qué decirte... se ve muy poco en la facultad y después yo me dediqué a Parkinson porque es más interesante".

La prolongación en el tiempo, unida a la falta de conocimientos en torno a esta dolencia, hace que tanto para profesionales como para pacientes se trate de un dolor inmerso en incertidumbres que se trasladan al entorno cercano. Los problemas que describe a continuación Paula con su maestra de escuela primaria ponen en evidencia, por un lado, la ignorancia respecto de estos dolores de cabeza, que hace que se los asocie a cuestiones sin importancia. Entonces, según los sentidos de la gente que lo rodea, el migrañoso debe realizar determinadas actividades (como las tareas de la escuela) a pesar del malestar.

El problema era con las faltas que tenía por año y con las maestras, ya que ellas no lo entendían. A lo mejor faltaba bastantes veces en el año por el dolor y me tomaban de punto, yo estaba en séptimo ya, y me decían: 'iPero vos faltas mucho!', y yo le decía: 'Pero sufro de migraña'. Imagínate que yo tendría 12, 13 años en ese momento, hasta mi papá se los dijo. No importaba, me tenían de punto igual. No entendían, para ellas era un dolor de cabeza normal, no lo vivían como uno lo vive, que sentís... como que late la cabeza (Paula, 26 años).

No obstante, lo paradójico y particular de la migraña es que las dificultad para "creer" en un dolor "que no se ve" proviene más de las relaciones vinculares que desde los saberes biomédicos. El análisis de estos dolores de cabeza muestra que los relatos de los pacientes sobre experiencias con los dolores de cabeza adquieren para el saber biomédico un estatuto privilegiado, dada la especial relación que se establece entre dichos relatos y la construcción clínica del diagnóstico. Los profesionales sistematizan, objetivan e incorporan estos dichos como nociones médicas desprovistas de todo elemento subjetivo. Por ejemplo, la falta de tolerancia a la luz y a los ruidos son dos síntomas de la migraña que las personas describen y los profesionales los transforman en "procesos de fotofobia y sonofobia" (Del Monaco 2012). 


\section{perifèria}

Número 20 (1), junio 2015

http://revistes.uab.cat/periferia

Como señala a continuación un médico entrevistado, la migraña "no es cualquier cosa". Este aspecto también aparece en los relatos de los pacientes, quienes diferencian a los "dolores de cabeza que tiene todo el mundo con la migraña":

La gente suele llamar dolor de cabeza a cualquier cosa, pero la migraña tiene que tener ciertas características. Tiene que durar tanto tiempo, tener tal localización, agravarse con determinados factores, mejorarse con otros. Aparte, el tema es que te da náuseas, de la fotofobia, sonofobia, un movimiento que te puede aumentar el dolor (Médico neurólogo).

De hecho, que la migraña tenga un estatuto que tanto profesionales como pacientes diferencian de los "dolores de cabeza comunes" es posible debido a la atención puesta al escuchar estos relatos. Esta particularidad diferencia a estos dolores de otros que perduran en el tiempo, así como también permite discutir con estudios antropológicos que plantean la falta de reconocimiento de los médicos a los relatos de los pacientes. Al contrario, como se señaló anteriormente, sus manifestaciones subjetivas son recuperadas por los profesionales para construir el diagnóstico. Sin embargo, interesa resaltar que no se incluyen todas las manifestaciones sino sólo las que pueden traducirse e integrarse en un modelo que se asemeje al modelo de enfermedad biomédico.

Incluso, durante los momentos del diagnóstico $-y$, también, luego en los tratamientos- los pacientes atraviesan distintas experiencias con los médicos neurólogos. En algunos casos dicen que encuentran cierta "escucha" a su problema mientras que en otras oportunidades destacan las dificultades por las que atraviesan y la falta de "comprensión" que dicen percibir a su problema. Las referencias a "mirar muy técnico", "ponerse más en tu lugar" son algunas de las palabras que enuncian quienes tienen migraña en referencia a la biomedicina.

Viste cuando sentís que no te miran a los ojos... que esas necesidades que capaz uno tiene y va al médico, qué sé yo...Un acercamiento... una cercanía... no sé. Eran preguntas sobre la edad, cuándo me empezó el dolor... te juro... después no sé... agarró el análisis de sangre, la resonancia y miraba ¿viste? Ni siquiera 


\section{perifèria}

Número 20 (1), junio 2015

http://revistes.uab.cat/periferia

dialogaba conmigo... en ningún momento me dijo si estaba bien o estaba mal... Lo asumí yo porque no me dijo 'te queda poco tiempo de vida'. No me dijo nada grave... Pero como que escribió algunos datitos en la hoja y dice 'tenés que dejar de lado las angustias'... (Carolina, 24 años).

Carolina describe una experiencia durante una consulta médica, en la que el profesional "escribió algunos datitos" pero ella no siente un "acercamiento o cercanía" en esa relación. Este aspecto aparece con frecuencia en el conjunto de entrevistados y evidencia los síntomas que son tenidos en cuenta por los profesionales y aquellos que se "descartan" o dejan de lado. Dentro de estos últimos se encuentran los contextos locales en los que se padecen, las dimensiones de género, económicas, sociales, entre otras, que no tienen relevancia en la construcción diagnóstica del malestar.

En este sentido, uno de los entrevistados dice que "está bueno que se hagan estudios sobre la migraña para que los otros tengan más conciencia". En este grupo de personas que, de acuerdo a Eric (47 años) no tienen conciencia, no sólo se encuentran los profesionales sino también los jefes en los trabajos e, incluso, algunos familiares que "no entienden".

\section{Construcción diagnóstica: armar la categoría a partir de los relatos}

Las teorías biomédicas sobre las causas de la migraña son fragmentarias y, en algunos casos, contradictorias. En ellas se combina y discrimina lo "biológico" de lo "social". Dentro de lo "biológico" se encuentran los siguientes factores: ser mujer; ciertas condiciones genéticas, hereditarias u hormonales; mecanismos de "vasoconstricción" y "vasodilatación" que producen el dolor, entre otras. Los aspectos sociales incluyen una variedad de elementos dentro de la categoría de "estilo de vida", como tomar alcohol, comer ciertos alimentos, dormir mal, no realizar actividad física o realizarla en exceso, no manejar el estrés; es decir, múltiples situaciones que dificultan para los pacientes saber qué es lo que está produciendo los dolores de cabeza. En palabras de los profesionales, el diagnóstico "se basa en el relato del paciente": 


\section{perifèria}

Número 20 (1), junio 2015

http://revistes.uab.cat/periferia

El diagnóstico sigue siendo un diagnóstico clínico. Es basado en el relato del paciente, no necesitamos un estudio en particular. Uno lo hace para descartar otras cosas, pero no para hacer el diagnóstico. El diagnóstico es el relato, y el dolor crónico usa métodos complementarios para descartar, y también hay muchos que recaen... hay mucha responsabilidad del paciente (Médica neuróloga).

En el caso de la migraña, el concepto de enfermedad, en los términos en que la hemos definido anteriormente, se quiebra. En la consulta, entre las preguntas que pueden hacer los profesionales se encuentran las referidas a frecuencia e intensidad: cantidad de episodios de dolores de cabeza por mes y sus características, síntomas que los acompañan, momentos en el día en que suelen aparecer y si son asociados con algo en particular. También, se efectúan estudios complejos como tomografías computadas, electroencefalogramas o resonancias magnéticas, que permiten tomar imágenes del cerebro. Uno de los motivos por los cuales se realizan estos estudios es para descartar tumores, esclerosis, anomalías en el cerebro o accidentes cerebrales vasculares. Si los resultados se encuentran dentro de los parámetros esperados por la biomedicina, es decir, si no se registran alteraciones y/o anomalías, se pasa a una segunda instancia. A través de un proceso que denomino "apropiación (en parte) de las narrativas de los pacientes", los médicos diagnostican estos dolores como migraña. Este proceso consiste en la escucha y registro de una parte de las descripciones -susceptibles de ser sistematizadas con el resto de los pacientes- de las personas sobre sus dolores de cabeza. Es importante resaltar que esta "parte" del relato que los médicos recuperan es posible de ser convertida en una categoría biomédica que se pueda incorporar a manuales internacionales y revistas científicas relativas a esta práctica. Por eso, aquellos eventos particulares relacionados con experiencias de los pacientes se pasan por alto, ya que los profesionales se concentran en aquellas categorías que se repiten en los relatos con el objetivo de encontrar fragmentos que resulten modelizables en un símil de la noción de enfermedad.

Dado que en la construcción diagnóstica de la migraña conviven tanto saberes 


\section{perifèria}

Número 20 (1), junio 2015

http://revistes.uab.cat/periferia

expertos como legos, las experiencias que describen las personas que acceden a los hospitales son diferentes entre sí: "Bueno, uno trata de ir al médico para que te dé una solución, pero más o menos todos te dicen lo mismo" (Paula, 26 años).

La mayoría de los entrevistados reconocieron que, a pesar de recorrer distintos centros de salud en búsqueda de respuestas diversas, las explicaciones que encuentran son, en general, similares. El diagnóstico de la migraña se estandariza, así como también sus explicaciones y tratamientos:

El primer médico al que fui me dijo: 'Bueno, vos tenés que hacerte todos estos estudios. Si todo esto te da perfecto, es porque tenés migraña', me dijo. 'Si en esos estudios te sale algo, es porque tenés algo a nivel de la cabeza' (María Cecilia, 27 años).

Para las personas entrevistadas, concurrir a la consulta con profesionales de la salud en búsqueda de alivios y explicaciones se convierte en una experiencia, por lo menos, compleja y angustiante cuando la respuesta es: "si no tenés nada es porque tenés migraña". Sin embargo, estas frases son frecuentes en los neurólogos porque ellos también dicen no tener certezas respecto de este malestar. Además, los profesionales dijeron que "la migraña tiene un origen biológico pero todavía no se pudo aislar el gen", es decir que tanto ellos como los pacientes resaltan que "por el momento no hay nada que la cure".

La migraña es un tipo de cefalea primaria. Es un dolor intenso que limita al paciente, que tiene que dejar de hacer sus actividades. ¿Causa? No se sabe, hay varias teorías pero ninguna demostrada (Médica neuróloga).

No obstante, los especialistas ensayan una serie de modelos etiológicos para explicar posibles motivos de la migraña. Si bien en la mayoría de los casos se combinan distintos factores, en sus relatos prevalecen algunos aspectos por sobre otros. En ocasiones se le da prioridad al aspecto genético y hereditario del dolor. Plantear una genealogía del dolor que proviene de cuestiones genéticas se convierte en una de las explicaciones que encuentran mayor "legitimidad" en 


\section{perifèria}

Número 20 (1), junio 2015

http://revistes.uab.cat/periferia

distintos grupos sociales con los que interactúan los pacientes.

Es hereditaria, eminentemente genética-hereditaria. Es decir, en la familia, cuando hay un migrañoso siempre hay otros con migraña, no se da de forma esporádica. Es una enfermedad genética, o sea que hay grupos familiares que la padecen y es más frecuente en las mujeres que en hombres en una relación de 4 a 1 . Es una alteración a nivel cerebral. Lo que pasa es que en general los pacientes no saben, no han considerado que es un problema importante, entonces es difícil de detectar la herencia, pero si uno les insiste y pregunta seguramente van a encontrar un antecedente familiar (Médica neuróloga).

A pesar de que la genética es una dimensión mencionada como posible causa de la migraña, no hay estudios que certifiquen como tal al factor genético. De modo tal que las explicaciones se reducen a señalar que "si uno pregunta e insiste, alguien con migraña en la familia encontrás". No obstante, en caso de que los pacientes mencionen la existencia de un tío abuelo de parte de la madre que nunca conocieron con migraña: ¿es posible fundamentar el dolor en esa relación?

Otra de las explicaciones biomédicas que, al igual que la herencia, son preponderantes en la migraña es el género. Las mujeres tienen más dolores de cabeza que los varones y esta afirmación es justificada biomédicamente por estudios epidemiológicos que dicen que la migraña afecta mundialmente a un 1617\% (Zavala y Sarabia 2006 2008). Asimismo, algunos médicos dijeron que después de la menopausia disminuye la frecuencia de los dolores de cabeza. Sin embargo, algunas entrevistadas mayores de cincuenta años mencionaron: "tenía la esperanza de que con la menopausia se me fueran los dolores, pero sigo igual".

Igual acá es la primera vez que consulto, porque lo dejás para mañana, para pasado, ya se me pasa... después te conformás con que tu familia es migrañosa, porque mi mamá y mi abuela también lo son... y como me dijeron que es hereditario y no tiene cura, lo vas dejando pasar (Carla, 36 años). 


\section{perifèria}

Número 20 (1), junio 2015

http://revistes.uab.cat/periferia

Atribuir los dolores de cabeza a dimensiones de género y/o hereditarias construye una genealogía del dolor que se encuentra ligada o busca sustentarse en aspectos biológicos (ser mujer o tener un familiar con migraña, consecuentemente, transmisión genética). Al mismo tiempo, estas explicaciones biomédicas, rodeadas de mayor o menor legitimidad, si bien buscan fundamentarse en la biología, no permiten comprobar dicha relación. Es por eso que, como se analiza a continuación, a ellas se les suelen agregar los "estilos de vida" de los pacientes y, de esta forma, se argumenta una multicausalidad del dolor.

En la migraña seguro es multifactorial. Primero porque no se sabe de dónde viene, así que tiene que haber varias cosas que uno no puede identificar... cierta predisposición genética hay... y sobre esa base genética influyen otras cosas, el medio, la parte del estrés, el estado de ánimo, todo eso influye y se mezcla y desencadena en una migraña. Una base orgánica tiene seguro, pero lo cierto es que el mal dormir, el estrés, el mal descanso influyen (Médica neuróloga).

Una tercera referencia etiológica reside en el modelo epidemiológico del "estilo de vida". Fundamentados en esta noción que proviene de la epidemiología, los profesionales resaltan la necesidad de que los sujetos modifiquen comportamientos y hábitos que posiblemente ejerzan influencia en los dolores de cabeza (Del Monaco 2012).

Más aún, como menciona una médica a continuación, en la migraña son fundamentales las "medidas higiénico-dietéticas", es decir, numerosos cambios en la vida cotidiana.

3 El estilo de vida es, según la Organización Mundial de la Salud: [...] una forma de vida que se basa en patrones de comportamiento identificables, determinados por la interacción entre las características personales individuales, las interacciones sociales y las condiciones de vida socioeconómicas y ambientales. Los estilos de vida individuales, caracterizados por patrones de comportamiento identificables, pueden ejercer un efecto profundo en la salud de un individuo y en la de otros. Si la salud ha de mejorarse permitiendo a los individuos cambiar sus estilos de vida, la acción debe ir dirigida no solamente al individuo, sino también a las condiciones sociales de vida que interactúan para producir y mantener esos patrones de comportamiento (OMS, 1998: 9) 


\title{
perifèria
}

Número 20 (1), junio 2015

http://revistes.uab.cat/periferia

\begin{abstract}
"Que tengan una vida ordenada, que traten de evitar o manejar el estrés...O sea, se les dan pautas para que ellos tomen conciencia de cuáles son las cosas que tienen que tratar de manejar de otra forma. Que conozcan su enfermedad y que sepan cuáles son los factores que la pueden desencadenar. Yo entonces les digo a los pacientes que traten de investigar qué les hace mal, para tratar de evitarlo y modificarlo (Médica neuróloga).
\end{abstract}

A lo largo de esta investigación se repiten entre los médicos descripciones similares en las que el foco se pone especialmente en lo que hacen los pacientes. Esos relatos permiten inferir que los dolores de cabeza son resultado de ciertas prácticas y comportamientos en la cotidianidad. Esta combinación de cuestiones biológicas y sociales modifica la noción que desde la biomedicina se tiene, en algunos casos, de los pacientes como epifenómenos de acontecimientos que suceden en el cuerpo (Le Breton 1999 2010) e incorpora nuevas formas de entender al padecimiento.

Frente a la dificultad de explicar ciertos padecimientos, la medicina plantea que la complejidad de determinadas enfermedades requiere que se incorpore el control de las vidas cotidianas de los pacientes para dar cuenta de etiologías y tratamientos (Epele 1997). La noción de estilo de vida ofrece herramientas para ampliar las explicaciones biomédicas sobre ciertas dolencias, y extiende los motivos de la causalidad y responsabilidad hacia el lado de los pacientes. Si bien se recuperan los dichos de los pacientes, también se les exige "compromiso" y un conjunto de acciones para la reducción de sus dolores de cabeza.

No obstante, en la mayoría de los casos y de los dichos provenientes de los saberes expertos estas tres explicaciones confluyen y conviven y, por momentos, las teorías por medio de las cuales se intenta explicar qué es lo que produce los dolores de cabeza se tornan difusas. Más aún, si bien en los dichos de los profesionales se identifican ciertas explicaciones al respecto, se desconoce por qué en condiciones similares algunas personas tienen migraña y otras no.

En las entrevistas, la mayoría de los profesionales concuerdan con que "algo orgánico hay", es decir, "existe" un proceso biológico y neurológico que produce la migraña, aunque se desconoce cuál es. También coinciden en la imposibilidad 


\section{perifèria}

Número 20 (1), junio 2015

http://revistes.uab.cat/periferia

de hablar de una cura y, consecuentemente, en la necesidad de que los pacientes se comprometan a tener constancia en los tratamientos y en los cambios de sus modos de vida.

En cuanto a las ambigüedades y diferencias entre los profesionales, se encuentra el mayor o menor protagonismo otorgado a lo biológico y a la cuestión genética. En algunos casos se habla de una relación lineal entre la herencia y tener migraña, "se nace o no con esa predisposición". En otros, si bien se reconoce que existe predisposición familiar, se destaca o privilegia el papel del medio de influir en el padecimiento.

No obstante, lo que muestra la migraña es que frente a las pretensiones de ciencia objetiva, ciertos malestares y padecimientos deben reunir una serie de requisitos para ser considerados y legitimados por la disciplina biomédica.

\section{"Rogaba que me dijera: 'Tenés un tumor del tamaño de una manzana" "}

Las ambigüedades y la falta de certidumbre que genera la migraña como diagnóstico médico (en comparación con otras dolencias) implica descripciones, por parte de muchos entrevistados, en las que se destaca el grado de confusión que implica tanto para ellos como para su entorno "tener una enfermedad donde todos los estudios te dan bien, es como si no tuvieras nada".

Ya me hicieron tomografía, pero mi mamá quiere una resonancia magnética porque dice que en colores sale mejor por si llega a ser otra cosa. Y claro, creo que en el último año fui a todos los neurólogos para ver qué me hacen, quién me manda una resonancia. Pero todos me dicen que no hace falta, que es migraña, que está todo bien (Paula, 26 años).

Paula dice tener dolores de cabeza desde los cinco o seis años, y describe la preocupación y el acompañamiento constantes de su madre. La entrevista a continuación fue realizada a Vanesa, una paciente con migraña que estaba en el hospital en compañía de su novio. Durante los relatos se mezclaron descripciones de ambos que muestran situaciones ante dolores en los que "no te sale sangre, 


\section{perifèria}

Número 20 (1), junio 2015

http://revistes.uab.cat/periferia

entonces no sé qué hacer":

Si vos no sos médico... o sea... yo hice un curso de reanimación y he salvado vida de gente en accidentes pero eso es una cosa y los dolores de cabeza, otra. O sea, a vos te duele la cabeza y yo ¿qué hago? Sé qué hacer si te agarra un ataque de presión. Pero no sé qué hacer si te duele la cabeza. Y menos como ella... Yo no sé si exagera, si no exagera... es raro porque si te veo sangre sé que hacer pero con esto no (Nicolás, pareja de mujer con migraña Vanesa, 34 años).

El relato de Nicolás describe una situación cotidiana en la que a Vanesa le empieza a doler la cabeza y en él conviven desde percepciones de exageración hasta preocupación y dudas por "no saber qué hacer". Sin embargo, reconoce que, a pesar de las ambigüedades del dolor, no lo pone en duda (algo que sí le sucede a la entrevistada en su ámbito laboral):

En el trabajo hasta que no me vieron, no me creyeron. $Y$ me llamaron para decirme que deje de faltar porque tenía muchas faltas y no las puedo tener por un dolor de cabeza. Bueno les dije, voy a seguir viniendo, si me descompongo acá me llaman una ambulancia. Pasaron dos semanas de la conversación y me descompuse y llamaron a la ambulancia y se pegaron un susto todos. O sea, hasta que no lo ven no lo creen (Vanesa, 34 años).

En este caso, el susto que según ella tuvieron en el ámbito laboral y la "creencia" en su dolor apareció cuando llegó una ambulancia, como representante, de algún modo, de la institución biomédica que legitima su malestar. Sin embargo, las personas con estos dolores no siempre llegan a descomponerse ni a llamar una ambulancia porque, según sus dichos, intentan "frenarlo antes".

A modo de broma, Lucrecia (55 años) dice: "lo único que te mandan a hacer es una tomografía y nada más. Me reía con mi hija porque se descubrió que en la cabeza no tengo nada" después de que los resultados de la tomografía prescripta por el médico ante la consulta por sus dolores de cabeza resultara bien. Sin embargo, 


\section{perifèria}

Número 20 (1), junio 2015

http://revistes.uab.cat/periferia

los dolores subsisten y por eso este tipo de dolencias crónicas tensionan no sólo los saberes biomédicos sino también los modos "tradicionales" de padecer, debido a su particular construcción diagnóstica y a sus características.

\section{Algunas reflexiones finales}

Las certezas que dicen necesitar los pacientes tanto para ellos como para su entorno cercano, en lugar de estudios que certifiquen que "está todo bien pero me sigue doliendo", queda sin efecto. No obstante, las nociones acerca de la salud, el cuerpo y la enfermedad han cambiado en las últimas décadas y por eso es necesario desfamiliarizar categorías presentes (Martín 1994). Entonces, si bien los estudios de imágenes constituyen una de las últimas opciones que tienen los médicos para "descartar cualquier cosa grave", los cambios y dolores como la migraña requieren otras concepciones para definir biomédicamente "lo grave" y "preocupante" de aquello que no lo es.

Es decir, hay barreras que impiden dar cuenta de ciertos malestares cuyas lógicas no se corresponden con diagnósticos biomédicos tradicionales. Incluso los pacientes como Carolina señalan que: "no se puede comprobar... digamos... si digo tengo fiebre me dicen 'bueno venite que te tomo la fiebre' pero 'tengo dolor de cabeza', ¿cómo lo comprobás?" (Carolina, 24 años). Es por eso que, teniendo el lugar hegemónico que todavía tiene la medicina basada en evidencia, numerosos entrevistados reconocieron preferir un daño peor (pero evidente) a la migraña.

Tener un "tumor de tamaño de una manzana", más allá de sus consecuencias, sería algo estandarizado, localizado, comprobable; entonces, ante un padecimiento, no sólo se busca volver al estado previo sino también permanecer dentro de lo que es "correcto" y "verificable" padecer. En cambio, entender los cuerpos situados contextualmente significa atribuir variaciones a la biología y situarla en tiempos y espacios que conforman realidades complejas. Es decir, los factores biológicos constituyen una parte de esas realidades, pero también hay que tener en cuenta aspectos socioeconómicos, de género, morales, violencias estructurales que producen corporalidades y desigualdades en los procesos de sufrimiento invisibilizados desde la perspectiva biomédica (Lock 1997 2010). De acuerdo con Wittgenstein: 


\title{
perifèria
}

Número 20 (1), junio 2015

http://revistes.uab.cat/periferia

\begin{abstract}
Supongamos que otra persona y yo tuviésemos en común una parte de nuestros cuerpos, digamos una mano. Imaginemos que una avispa pica el brazo. Los dos gritamos, hacemos gestos de dolor y damos la misma descripción del dolor, etc. ¿Diremos ahora que tenemos el mismo dolor o dolores diferentes? Si en tal caso alguien dice: 'sentimos dolor en el mismo sitio, en el mismo cuerpo, nuestras descripciones coinciden, pero aún con todo mi dolor no puede ser suyo', yo supongo que se inclinará a decir: 'porque mi dolor es mi dolor y su dolor es su dolor' (Wittgenstein 1968: 87).
\end{abstract}

La biología -como categoría neutral y objetiva- se fractura frente a este tipo de diagnósticos y dolencias y, en su lugar, ingresan múltiples biologías que refieren a los modos de padecer en contextos situados y articulados con otras dimensiones de la cotidianidad. La construcción diagnóstica de la migraña combina saberes legos y expertos. Por un lado, la mayoría de los entrevistados mencionaron que en sus intentos por buscar alivio y explicaciones a sus dolores describen eventos, experiencias y situaciones que son recogidas -en parte- por los profesionales y dan forma a una categoría "biomédica" estandarizada cuyo diagnóstico está a cargo de la neurología. Sin embargo, el análisis de las narrativas permite ver cómo los relatos de los médicos, quienes padecen y vínculos cercanos se superponen y contradicen entre sí.

\section{Bibliografía}

Camargo, Kenneth (1997). "A Biomedicina" PHYSIS. Revista de Saúde Coletiva 7(1): 45-68.

Del Monaco, Romina (2012). "Dolores de cabeza, síntomas y enfermedad. Un abordaje social sobre la construcción clínica de la migraña". Intersecciones en Antropología 13: 501-511. http://dx.doi.org/10.7440/antipoda19.2014.06

(2013). "Autocuidado, adherencia e incertidumbre: tratamientos 


\section{perifèria}

Número 20 (1), junio 2015

http://revistes.uab.cat/periferia

biomédicos y experiencias de pacientes en el dolor crónico de la migraña". Salud colectiva 2013, vol.9, n.1, pp. 65-78. http://dx.doi.org/10.1590/S185182652013000100006

Dias Duarte, Luis Fernando (2003). "Indivíduo e pessoa na experiencia da saúde e da doenca". Ciencia y Saúde Colectiva, 8 (1): 173-183. http://dx.doi.org/10.1590/S1413-81232003000100013

Epele, María (1997). "La lógica del (Auto) cuidado y sus consecuencias en la Institucionalización del VIH/SIDA". Trabajo presentado en el $\mathrm{V}$ Congreso de Antropología Social. La Plata Argentina.

Foucault, Michel (2008). La hermenéutica del sujeto. Buenos Aires: Fondo de Cultura Económica.

Grimberg, Mabel (2000). "Género y VIH-Sida. Un análisis de los diferenciales de género en la experiencia de vivir con VIH". Cuadernos Médico Sociales, 78, Rosario, 41-54.

(2003). "Narrativas del cuerpo. Experiencia cotidiana y género en personas que viven con VIH". Cuadernos de Antropología Social, núm. 17, pp.79-99.

(editora) (2009). Experiencias y narrativas de padecimientos cotidianos. Miradas antropológicas sobre la salud, la enfermedad y el dolor crónico. Buenos Aires: Antropofagia.

Good, Byron (1994a). Pain as Human experience. An anthropological perspective. Berkeley: University of California Press.

(1994b) Medicine, Rationality and Experience. An Anthropological Perspective. Cambridge: Cambridge University Press. 


\section{perifèria}

Número 20 (1), junio 2015

http://revistes.uab.cat/periferia

Harvey, David (2005). Breve historia del neoliberalismo. Madrid: AKAL.

Jackson, Jean (2000). "Camp Pain" Talking with Chronic Pain Patients. Philadelphia: University of Pennsylvania Press.

(2005). "Stigma, liminality and chronic pain: mind-body borderlands". American Ethnologist, vol. 32, N03, pp. 332-353. DOI: 10.1525/ae.2005.32.3.332

Kleinman, Arthur (1994). "The Deligitimation and Religitimation of Local Worlds". En: Brodwin, P., Kleinman, A., Good, B., Del Vecchio Good, M., (eds.) Pain as Human experience. An anthropological perspective. Berkeley: University of California Press, pp.169-197.

Le Breton, David (1999). Antropología del dolor. España: Seix Barral.

(2010). Antropología del cuerpo y la modernidad. Buenos Aires: Nueva Visión.

Lock, Margaret; Das, Veena; Kleinman, Arthur (editors) (1997). Social Suffering. Los Angeles: University of California Press Berkley.

Lock, Margaret; Nguye, Vinh-Kim (2010). An anthropology of Biomedicine. Oxford: Wiley-Blackwell.

Martin, Emily (1994). Flexible bodies: tracking immunity in American Culture -from the days of Polio to the edge of AIDS. Massachusetts: Beacon Press.

Margulies, Susana; Barber, Nélida; Recoder, María Laura (2006). VIH-SIDA y "adherencia" al tratamiento. Enfoques y perspectivas. Antípoda, Revista de Antropología y Arqueología número 003, pp. 281-300.

Margulies, Susana (2010). "Etiología y riesgo en la construcción clínica de la 


\section{perifèria}

Número 20 (1), junio 2015

http://revistes.uab.cat/periferia

enfermedad VIH-sida. Ensayo de antropología de la medicina". Intersecciones en Antropología 11: 215-225.

Organización Mundial de la Salud (2012). "Cefaleas". Disponible en: http://www.who.int/mediacentre/factsheets/fs277/es/ [Última consulta: marzo de 2013].

Sontag, Susan (2003). La enfermedad y sus metáforas. El sida y sus metáforas. Buenos Aires: Taurus Alfaguara.

Wittgenstein, Ludwig (1968). Los cuadernos azul y marrón. Madrid: Tecnos s.a.

Zavala, Héctor; Saravia, Bibiana (2006). "Impacto de la migraña en la calidad de vida". Revista del Hospital J.M. Ramos Mejía. Edición Electrónica, vol XI, no3. Buenos Aires. Disponible en: http://hospitalramosmejia.info/r/200603/4.pdf [Última consulta: mayo 2015]. 